\title{
Multiwall Carbon Nanotube-Induced Apoptosis and Antioxidant Gene Expression in the Gills, Liver, and Intestine of Oryzias latipes
}

\author{
Jin Wuk Lee, ${ }^{1}$ Young Chul Choi, ${ }^{2}$ Rosa Kim, ${ }^{3}$ and Sung Kyu Lee ${ }^{1}$ \\ ${ }^{1}$ Gyeongnam Department of Environmental Toxicology and Chemistry, Korea Institute of Toxicology, Jin-Ju, \\ Gyeongsangnam-do 660-844, Republic of Korea \\ ${ }^{2}$ CNT Research Group, R\&D Center, Hanwha Chemical Corporation, 76 Gajeong-ro, Yuseong-gu, Daejeon 305-804, Republic of Korea \\ ${ }^{3}$ Environmental Biology Research Center, Gyeongnam Department of Environmental Toxicology and Chemistry, \\ Korea Institute of Toxicology, Jin-Ju, Gyeongsangnam-do 660-844, Republic of Korea
}

Correspondence should be addressed to Sung Kyu Lee; sungklee@kitox.re.kr

Received 29 June 2014; Accepted 1 November 2014

Academic Editor: Mary Gulumian

Copyright (C) 2015 Jin Wuk Lee et al. This is an open access article distributed under the Creative Commons Attribution License, which permits unrestricted use, distribution, and reproduction in any medium, provided the original work is properly cited.

Multiwall carbon nanotubes (MWCNTs) have many attractive properties with potential applications in various fields. Despite their usefulness, however, the associated waste can be hazardous to the environment. To examine adverse effects in aquatic environments, Oryzias latipes were exposed to MWCNTs dispersed in water for 14 days and apoptosis and antioxidant gene expression were observed. This work showed that in gills exposed to $100 \mathrm{mg} / \mathrm{L}$ MWCNTs for 4 days, there was significant p53, caspase-3 (Cas3), caspase-8 (Cas8), and caspase-9 (Cas9) gene expression relative to the controls, while catalase (CAT) and glutathione-S-transferase (GST) expression were reduced. At 14 days, CAT, GST, and metallothionein (MT) were induced significantly in the gills and Cas3, Cas8, and Cas 9 were induced in the liver. No significant gene induction was seen in intestine. Intracellular reactive oxygen species (ROS) were increased significantly only at 14 days. Histologically, no apoptosis was observed with exposure to $100 \mathrm{mg} / \mathrm{L}$ MWCNTs for 21 days. The gills were more sensitive to MWCNT toxicity than the other organs. Males had higher apoptosis gene induction than females. These results demonstrated that MWCNTs could cause apoptosis in a manner influenced by tissue and gender in aqueous environments.

\section{Introduction}

Aquatic environments are the ultimate sink for many contaminants, via either direct discharge or hydrological and atmospheric processes. Since fish occur in virtually all aquatic environments and play a major role in aquatic food webs, fish are useful for monitoring pollutants in aquatic environments [1]. Oryzias latipes has been used widely as an experimental fish for monitoring pollutants for over a century [2]. Fish liver is a major detoxification organ and the gills and intestine are useful monitor organs that reflect the health of aquatic organisms and have been used as target organs in aquatic toxicity studies [3-5].

Multiwall carbon nanotubes (MWCNTs) have many attractive electrical, mechanical, and thermal properties with potential applications in engineering, electronics, and medicine [6-8]. Nevertheless, MWCNTs are potentially very harmful environmental pollutants because of three major factors: the shape of the particles; their surface reactivity; and their clearance difficulty [9]. To improve the mechanical properties of MWCNTs, sufficient wetting and uniform dispersion in various media, including aqueous solutions, are required $[6,10]$. Therefore, it is possible that wastewater containing dispersed MWCNTs can be introduced into aquatic environments, where they might have hazardous effects.

The previous studies have demonstrated that MWCNTs cause oxidative stress and apoptosis both in vivo and in vitro. Rainbow trout (Oncorhynchus mykiss) exposed to Dietary SWCNT showed significant elevation of TBARS indicative of oxidative stress [11]. Chlorella vulgaris exposed to MWCNT 
produced an increase in the level of the antioxidant enzyme superoxide dismutase (SOD) [12]. MWCNT-induced pulmonary toxicity and the expression of proteins related to apoptosis (caspase-3 and caspase-8) were observed on exposing $\mathrm{BALB} / \mathrm{c}$ mice to aerosolized MWCNTs [9]. Increased apoptosis and caspase-3, caspase-8, and caspase- 9 protein activity were observed in RAW 264.7 cells exposed to acidtreated and taurine functionalized MWCNTs [13]. Dosedependent cytotoxicity in RAW 264.7 macrophages and A549 cells was observed as membrane leakage, liquid peroxidation, activation of the NF- $\kappa \mathrm{B}$ signaling pathway, the secretion of cytokines and chemokines, and protein release $[8,14]$. Activating caspase-3 and caspase-7 led to MWCNT-induced apoptosis in vitro [15]. MWCNTs activated several apoptosisinducing factors in rat LE cells, including p53, p21, and Bax protein [16]. Although the CNT-induced antioxidant expression and apoptosis occurrence have not been previously observed in aquatic organisms, other nanoparticles caused this kind of response. Zebrafish (D. rerio) exposed to silver nanoparticles showed an increase in both p53-related proapoptotic genes (e.g., $\mathrm{Bax}$ ) and parameters of oxidative stress (e.g., malondialdehyde) [17]. Juvenile common carp ( $C$. carpio) exposed to $\mathrm{TiO}_{2}$ revealed the reduction of antioxidant enzyme activity and apoptosis in hepatocytes and an increase in lipid peroxidation [18]. Copper nanoparticles produced an increase in malondialdehyde levels and in the number of apoptotic cells, but a decrease in SOD activity in juvenile Epinephelus coioides [19].

Apoptosis is a programmed cell death pathway that is essential in the development of multicellular organisms and functions in the maintenance of homoeostasis. The abnormal induction of apoptosis can cause various diseases, such as neurodegenerative and cardiovascular diseases [20,21]. It has been reported that caspase-3 (Cas3), Cas8, and Cas 9 gene induction causes apoptosis, and several factors can influence apoptosis and antioxidant gene expression, such as gender and tissue type [13, 22-28].

The exact mechanism of MWCNT-induced ROS production and apoptosis is unclear, although frustrated phagocytosis and the Fenton reaction caused by metal impurities introduced with MWCNTs during their synthesis might play roles $[29,30]$. MWCNTs have a high aspect ratio and macrophages cannot lengthen sufficiently to enclose long nanotubes, resulting in incomplete or frustrated phagocytosis $[31,32]$. If frustrated phagocytosis occurs, superoxide produced in the macrophage phagosome is released into the extracellular and intracellular space. This superoxide fluxes can lead to oxidative stress, apoptosis, inflammation, and so on $[13,33,34]$. In addition, metals such as iron induce hydroxyl radicals via the Fenton reaction and ROS have been recognized as inducers of apoptosis [35-37].

Although it has been postulated that wastewater containing dispersed MWCNTs can cause abnormal apoptosis and inflammation in aquatic species, only their toxicity was studied [11, 38-42]. Moreover, no investigations were conducted to assess apoptosis by MWCNTs in fish and in other aquatic organism. Therefore, we have investigated the MWCNT-induced antioxidant (catalase (CAT), glutathione$S$-transferase $(G S T)$ ), metallothionein $(M T)$, and apoptosis (caspase 3 (Cas3), caspase 8 (Cas8), caspase 9 (Cas9), and p53) gene expression of Oryzias latipes in fish in an aquatic environment. In addition, gender, tissue, and temporal differences in gene expression were evaluated.

\section{Materials and Methods}

2.1. Chemicals. HCO-40 (PEG-40 hydrogenated castor oil) was received from LG Household \& Care Ltd. (Seoul, South Korea). MWCNT was received from Hanwha chemical Co., Ltd. (Seoul, South Korea). The other chemicals used in this study were purchased from Sigma-Aldrich Co. (St. Louis, MO, USA).

2.2. MWCNT Dispersion and the Characterization of MWCNTs. According to the manufacturer's product datasheet, the MWCNTs were produced via a catalytic chemical vapor deposition process and purified to over $90 \%$, with the major impurities being the metals $\mathrm{Al}(\sim 2.3 \mathrm{wt} \%), \mathrm{Fe}(\sim 0.7 \mathrm{wt} \%)$, and Mo ( $\sim 0.15 \mathrm{wt} \%)$. They had diameters of $10-15 \mathrm{~nm}$, an average length of $20 \mu \mathrm{m}$, and a bulk density of $0.035 \mathrm{~g} / \mathrm{mL}$ (Figure 1). The particle size and Zeta potential of the MWCNTs were characterized using dynamic light scattering (DLS; Zetasizer nanoseries, nano-zs90, Malvern Instruments, Worcestershire, UK). To analyze the suspension stability index of the MWCNTs, the ultraviolet- (UV-) absorbance $(\lambda=550 \mathrm{~nm})$ was measured using a UV-vis spectrophotometer (Lambda 25, PerkinElmer, MA, USA). The suspension stability index of the MWCNTs at $100 \mathrm{mg} / \mathrm{L}(100 \mu \mathrm{g} / \mathrm{mL})$ is expressed as the $\%$ of the initial absorbance $(\lambda=550 \mathrm{~nm})$ at time 0 for MWCNTs suspended in water for 42 and $72 \mathrm{~h}$ after dispersion (Figure 2). The morphology of the MWCNTs was investigated using scanning electron microscopy (SEM; JEOL JSM 6700F, JEOL, Tokyo, Japan) (Figure 1(a)) and transmission electron microscopy (TEM; FEI Tecnai 20, 200 kV, FEI, Hillsboro, OR, USA) (Figure 1(b)).

2.3. Fish Care. Oryzias latipes were received from the aquarium of the Environmental Toxicology Center of Korea Institute of Toxicology, Jin-Ju, Gyeongsangnam Province, South Korea (5-month-old adult male and female fish; length = $2.9 \pm 0.36 \mathrm{~cm}$, weight $=0.27 \pm 0.11 \mathrm{~g}$ ). All fish were acclimatized in the laboratory for 1 month prior to the start of the study. Every morning and evening, they were fed $1 \%$ of their total weight using a commercial feed (tetramin tropical flake, Tetra Co., Melle, Germany). The acclimatization tank was filled with dechlorinated tap water and the tank water was changed once every 2 days. The photoperiod was a $12 \mathrm{~h}$ light/ $12 \mathrm{~h}$ dark cycle. Other conditions were maintained as follows: water temperature $=22 \pm 1^{\circ} \mathrm{C}$, dissolved oxygen $=>80 \%$, and $\mathrm{pH}=$ 6.8-7.4.

2.4. Oxidative Stress Assay. The intracellular reactive oxygen species (ROS) was measured with dichlorofluoresceindiacetate method. A DCF-DA stock solution of $10 \mathrm{mM}$ (in DMSO) was diluted 500-fold in Hank's balanced salt solution (HBSS; ThermoFisher scientific, Inc., Waltham, MA, USA) to yield a $20 \mu \mathrm{M}$ working solution. A 10 -mg sample of each tissue 


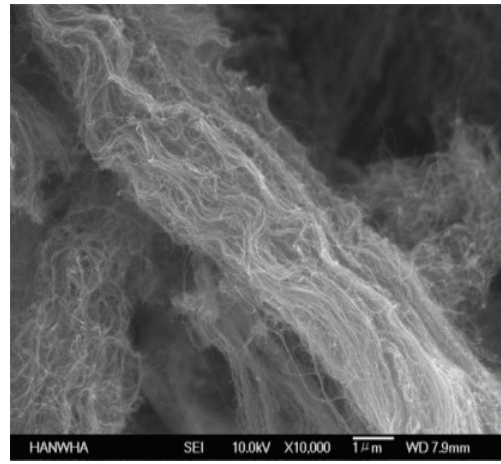

(a)

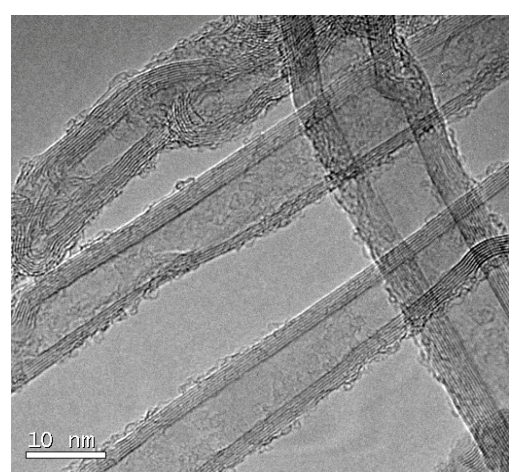

(b)

FIGURE 1: TEM and SEM image. (a) The morphology of the MWCNTs was captured using scanning electron microscopy image and (b) transmission electron microscopy image.

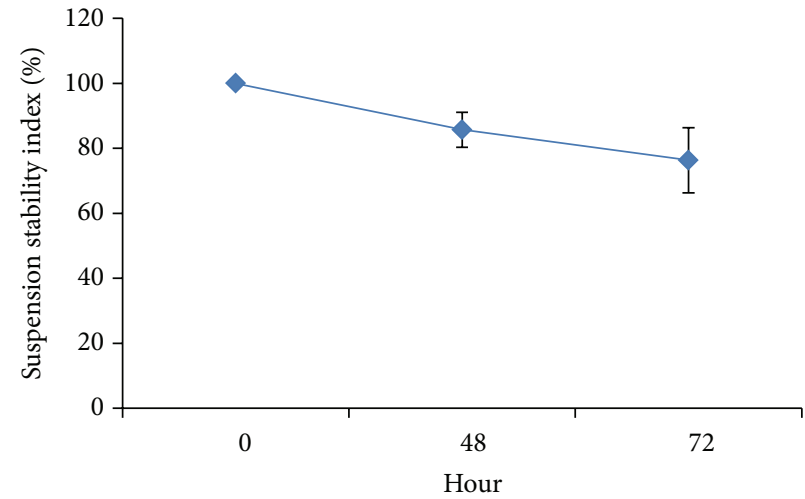

(a)

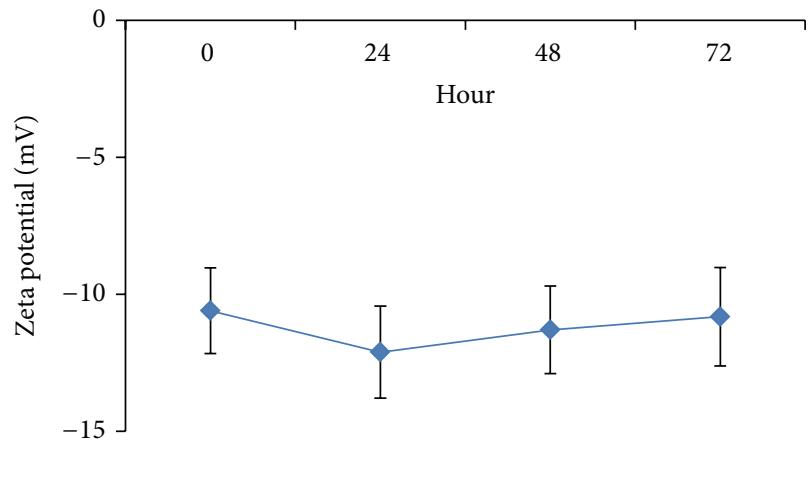

(b)

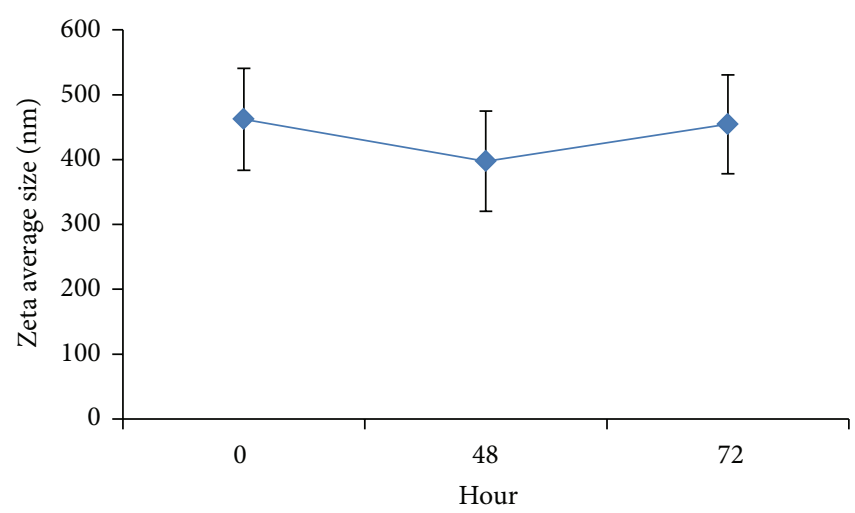

(c)

Figure 2: MWCNT dispersion state. (a) Suspension stability index. The suspension stability index of the MWCNTs at $100 \mathrm{mg} / \mathrm{L}$ (100 $\mu \mathrm{g} / \mathrm{mL}$ ) is expressed as the $\%$ of the initial absorbance $(\lambda=550 \mathrm{~nm})$ at time 0 for MWCNTs suspended in water for 42 and $72 \mathrm{~h}$ after dispersion. The spot shows the average stability index measured at every 0,48 , and $72 \mathrm{~h}$. (b) and (c) Zeta-potential value and Zeta average size: the Z-potential values and Zeta average size measure at every at every $0,24,48$, and $72 \mathrm{~h}$.

was homogenized with TissueLyser LT (Qiagen) in PROPREP protein (Intron Biotechnology Co., Seoul, Republic of Korea) extraction solution, according to the manufacturers' instructions. Following centrifugation at $13,000 \times$ g, protein in the supernatant was quantified by the Bradford assay. The $20 \mu \mathrm{g}$ protein from each tissue lysate was mixed with
DCF-DA working solution and the mixture was incubated for 3 hours at $37^{\circ} \mathrm{C}$ in the dark. Fluorescence of the samples was monitored at an excitation wavelength of $485 \mathrm{~nm}$ and an emission wavelength of $538 \mathrm{~nm}$ using fluorescence plate reader (Synergy H1 hybrid reader, BioTek instruments, Inc., Winooski, VT, USA). The result is shown in Figure 3. 


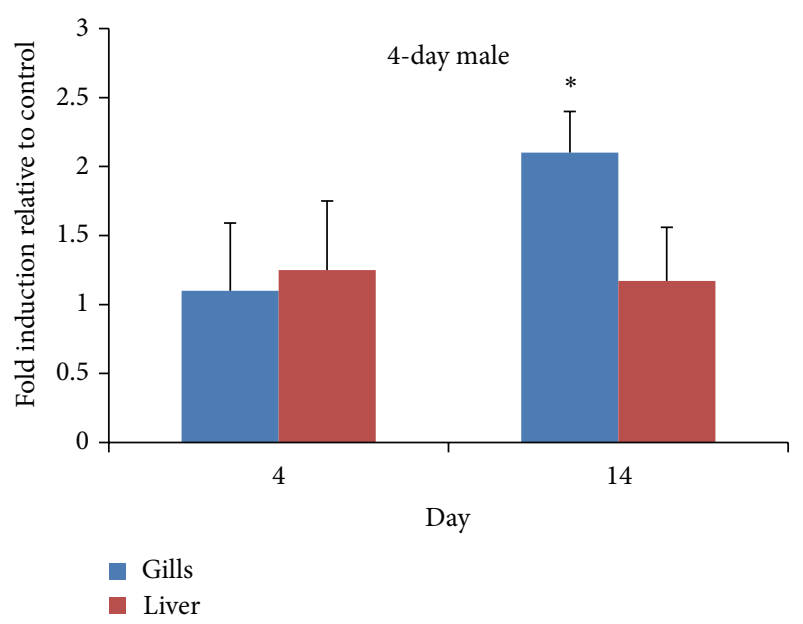

(a)

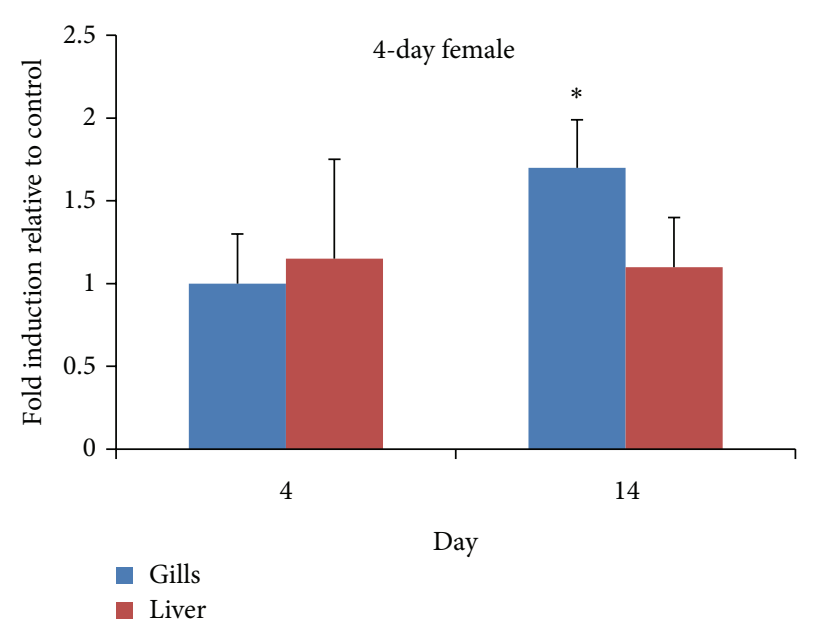

(b)

FIGURE 3: Intracellular ROS level. (a) Intracellular ROS induction level relative to control in male O. latipes exposed to $100 \mathrm{mg} / \mathrm{L}$ MWCNT. (b) Intracellular ROS induction level relative to control in female O. latipes exposed to $100 \mathrm{mg} / \mathrm{L}$ MWCNT. Columns and error bars represent the mean $\pm \mathrm{SD}$. Asterisk indicates values that are significantly higher than control values $\left({ }^{*} P<0.05 ; t\right.$-test, $\left.n=5\right)$.

2.5. Exposure Design. In this study, we select $100 \mathrm{mg} / \mathrm{L}$ $(100 \mu \mathrm{g} / \mathrm{mL}) \mathrm{MWCNT}$ as exposure concentration. The reason to select this concentration is that in preliminary test, statistically significant Cas3, Cas8, and Cas9 gene induction relative to control was confirmed in $100 \mathrm{mg} / \mathrm{L}$ MWCNT exposure. There was no significant gene induction in 1 and $10 \mathrm{mg} / \mathrm{L}$ MWCNT exposure. For the waterborne exposure, $100 \mathrm{mg}$ MWCNT was dispersed in $1 \mathrm{~L}$ distilled water containing $0.01 \%$ HCO-40 lipocol through sonication (56\% output, sonication for $10 \mathrm{~min}$, followed by a $5 \mathrm{sec}$ pause, repeat three times) with sonicator (GE 70T fisher scientific, Pittsburgh, PA,USA). After dispersion, each $1 \mathrm{~L}$ dispersed MWCNT solution was pooled into $7 \mathrm{~L}$ tank, and 25 O. latipes were administrated into it. The experimental tank was changed every 3 days for 14 days. And every 0 and 3 days, Zeta potential, Zeta average size, and UV absorbance at $550 \mathrm{~nm}$ for each treatment solution were measured using DLS and UVvis spectrophotometer (Figure 2). And another 25 fish were exposed to solvent control (HCO-40) $7 \mathrm{~L}$ tank containing $0.01 \%$ HCO- 40 for 14 days. We decapitated 5 fish from the acclimatization tank just before specimens were introduced into the treatment tank and used their liver and gills as the 0-day sample; that is, a calibrator that represents the amount of mRNA expressed at time zero in the control [43] (Livak and Schmittgen 2001). After exposure, at 4, 14 days, 7 O. latipes were decapitated. Liver, intestine, and gills were excised and extracted tissues were immediately immersed in RNA later solution (Qiagen, Valencia, CA, USA) according to the manufacturer's recommendations.

2.6. Primer Design. Beta-actin, Cas3, Cas8, Cas9, p53, metallothionein (MT), catalase, glutathione-s-transferase (GST) gene primer sequences were designed using the GenBank database described in Table 1 . For each primer, application efficiency test was performed; the slopes of each primer were within $95-105 \%$.
2.7. RNA Extraction and Real-Time PCR. Liver, gills, and intestine tissues preserved in RNAlater were homogenized with TissueLyser II (Qiagen) and total RNA was extracted using an RNeasy mini prep kit (Qiagen) according to the manufacturer's procedures. Total RNA quantity was estimated using a microspectrophotometer (Bio-prince SD 2000, China) at $260 \mathrm{~nm}$. The values for $260 / 280 \mathrm{~nm}$ were $2.01 \pm$ 0.05 (average \pm SD). To check the quality of the total RNA estimates, the bands for $28 \mathrm{~S}$ and $18 \mathrm{~S}$ ribosomal RNA from all samples were confirmed by $1 \%$ agarose gel electrophoresis. A $1 \mu \mathrm{g}$ RNA sample was reverse transcribed into cDNA using M-MLV reverse transcriptase (Promega Corp., Madison, WI, USA). Then $10 \mu \mathrm{L}$ Brilliant III ultra-fast SYBR Green QPCR Mix (Agilent Technologies, Santa Clara, CA, USA), $9 \mu \mathrm{L}$ cDNA (diluted to $1 / 50$ with DW), and 5 pmol $1 \mu \mathrm{L}$ primer were mixed and reacted in an Mx3000P qRT-PCR system (Stratagene, La Jolla, CA, USA). The $\beta$-actin housekeeping gene was used as a reference to normalize the expression levels. The PCR reaction cycle was conducted as follows: $94^{\circ} \mathrm{C}$ for $3 \mathrm{~min}$, followed by 40 cycles at $94^{\circ} \mathrm{C}$ for $20 \mathrm{~s}, 60^{\circ} \mathrm{C}$ for $15 \mathrm{~s}$, and $72^{\circ} \mathrm{C}$ for $15 \mathrm{~s}$. Melting curve analysis was performed to check the specific product. Real-time PCR data were obtained as threshold cycle $\left(C_{T}\right)$ values, and fold changes for relative gene expression to the calibrator were determined using the $2^{-\Delta \Delta \mathrm{CT}}$ method [43] (Livak and Schmittgen 2001). There was no significant change in beta-actin mRNA expression during 14 days (one-way ANOVA, $P<0.05$ ).

2.8. Statistical Analysis. The $t$-tests were used to detect significant effects between $100 \mathrm{mg} / \mathrm{L}$ MWCNT exposure and the corresponding control groups. A one-way ANOVA followed by Tukey's test was used to detect significant difference among treated groups. Data were expressed as means \pm SD. All data were analyzed using Minitab for windows software (Minitab Inc., State College, PA, USA). Prior to the ANOVA and 
TABLE 1: Primers used in this work.

\begin{tabular}{|c|c|c|c|}
\hline Gene & Accession number & Sequence & Product size (base pair) \\
\hline B-Actin-F & \multirow{2}{*}{ S74868.1 } & TCC ACC TTC CAG CAG ATG TG & \multirow{2}{*}{75} \\
\hline B-Actin-R & & AGC ATT TGC GGT GGA CG AT & \\
\hline Caspase 3-F & \multirow{2}{*}{ NM_001104670.1 } & TGG GTC CTC GTA ACG GTA CA & \multirow{2}{*}{131} \\
\hline Caspase 3-R & & TGG ACA TTT GGC GAA ACA GC & \\
\hline Caspase 8-F & \multirow{2}{*}{ NM_001104788.1 } & ACC GAG CCC CTA GCT TGA TA & \multirow{2}{*}{108} \\
\hline Caspase 8-R & & GCA TCC CCT TTC ACT TCC GA & \\
\hline Caspase 9-F & \multirow{2}{*}{ XM_004070317.1 } & CTG GCG ACG TAC AGT CTC AG & \multirow{2}{*}{81} \\
\hline Caspase 9-R & & AGT TGC AGC ATG TTC CTC GA & \\
\hline GST-F & \multirow{2}{*}{ XM_004085912.1 } & ACC TGC GAT CAC ACT GTT CA & \multirow{2}{*}{77} \\
\hline GST-R & & TTT GGA GAC TTC AGA GCC CA & \\
\hline MT-F & \multirow{2}{*}{ NM_001104785.1 } & CCG ACT CGA CTC TGA CAG AC & \multirow{2}{*}{88} \\
\hline MT-R & & CAG TCG CAG GGG TCC ATT AT & \\
\hline Catalase-F & \multirow{2}{*}{ XM_004069460.1 } & GCG GTA CAA CAG CGC AGA TG & \multirow{2}{*}{170} \\
\hline Catalase-R & & GGA TGG ACG GCC TTC AAG TT & \\
\hline P53-F & \multirow{2}{*}{ U57306.1 } & GTT CGT AGC TTC CCG GGT AG & \multirow{2}{*}{85} \\
\hline P53-R & & GAT TGA GCC AGT TCC CAC CA & \\
\hline
\end{tabular}

MT: metallothionein; GST: glutathione-s-transferase; B-actin: beta-actin.

$t$-test, normality test for data was performed with AndersonDarling test. F-test and Levene's tests were carried out to evaluate homogeneity of variance. A $P$ value less than 0.05 were considered significant.

\section{Results}

3.1. MWCNT Characterization. As seen in the TEM and SEM micrographs, MWCNTs, not some other form of carbon nanoparticle or amorphous carbon, were present (Figure 1). To analyze the dispersed state of the MWCNTs, we observed the stability index, Zeta potential, and Zeta average size (Figure 2). During exposure period, the suspension was maintained at over $73 \%$ and there was no significant alteration in the Zeta potential or Zeta average size during exposure. The tank water in which the MWCNTs were dispersed was replaced every 3 days. Figure 2 showed the dispersal status of the MWCNTs in water containing $0.01 \%$ HCO-40. Therefore, any toxicological outcomes identified in this study can be attributed to exposure to MWCNTs.

3.2. Oxidative and Metal Stress. The oxidative stresses induced by MWCNTs were investigated by examining intracellular ROS and GST and CAT gene expression. Significant antioxidant gene induction was observed at 14 days of MWCNT exposure (Figure 5). In addition, at 4 days, significant reductions in CAT and GST expression in the gills were observed (Figure 4). Relative to the control, the GST and $C A T$ reduction in males at 4 days was ca. three- and twofold, respectively, and, at 14 days, the GST and CAT induction was roughly 7 - and 17-fold (Figures 4 and 5). In females the respective GST and CAT reduction was ca. 2.3- and 2-fold at 4 days and GST and CAT induction was 9- and 4-fold at 14 days. Significant MT gene expression was induced 10- and 7fold relative to the control at 14 days in the gills of males and females, respectively.
Examining the gender differences in the gills, at 4 days, CAT and GST expression in the gills was reduced significantly, while $M T$ expression was unchanged, although only the reduction in CAT differed significantly between males and females. At 14 days, the average levels of induction of $M T$ and CAT were higher in males, while GST expression was higher in females, although the difference was significant only for CAT (one-way ANOVA, $P<0.05$ ).

Differences in expression were observed among the gills, liver, and intestine. At 4 days, GST and CAT expression were reduced significantly relative to the controls, while in the liver no significant reduction was found. At 14 days, in the gills, GST, CAT, and MT expression were induced significantly relative to the control, while in the liver there was no significant induction. In the intestine, no significant expression of oxidative stress genes was observed.

3.3. Apoptosis Gene Expression. MWCNT-induced apoptosis was investigated by examining $p 53, \mathrm{Cas} 3, \mathrm{Cas} 8$, and $\mathrm{Cas} 9$ gene expression. At 4 days, p53, Cas3, Cas8, and Cas 9 expression was increased significantly relative to the controls and was found with $100 \mathrm{mg} / \mathrm{L}$ MWCNT exposure in the gills of both females and males (Figure 4). The expression of the p53, Cas3, Cas8, and Cas 9 genes in the gills of males was increased 5-, 5-, 7-, and 11-fold, respectively, while that in the gills of females was increased 2-, 2-, 2.5-, and 4-fold, respectively. At 14 days, significant induction of $\operatorname{Cas} 3, \operatorname{Cas} 8$, and $\operatorname{Cas} 9$ gene expression relative to the controls was found in the livers of both females and males (Figure 5). The expression of Cas3, Cas8, and Cas 9 was increased 5-, 2.5-, and 7-fold, respectively, in males and 4-, 2-, and 3-fold in females.

There was a gender difference in apoptosis gene expression. The induction of Cas3, Cas8, Cas9, and $p 53$ expression relative to the controls was significantly higher in males than females. At 14 days, the average fold induction relative to the 


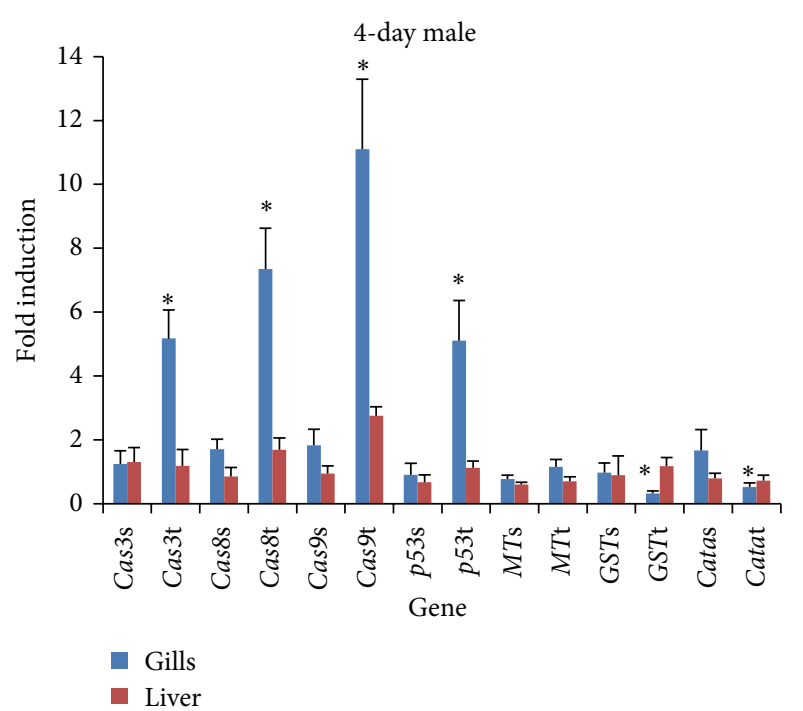

(a)

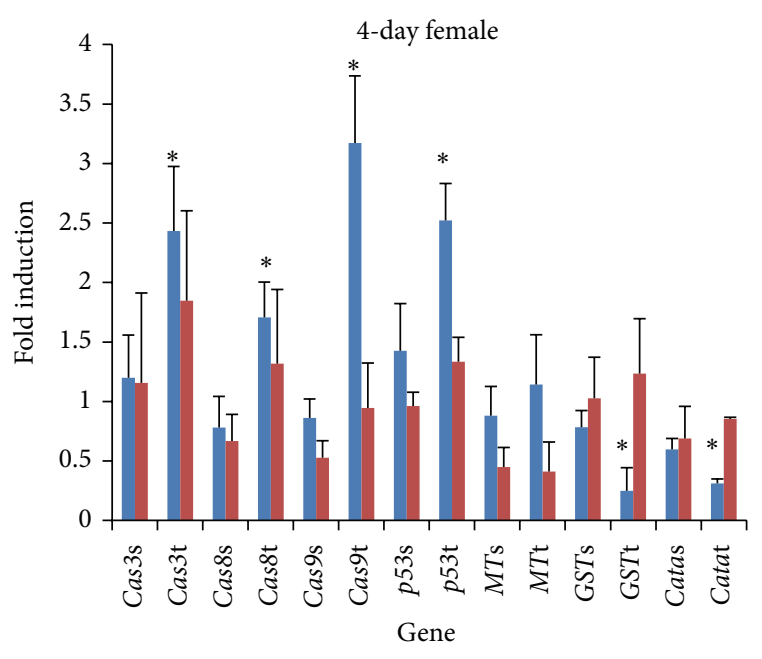

- Gills

- Liver

Figure 4: mRNA induction at 4 days. (a) Gene expression pattern of male O. latipes exposed to $100 \mathrm{mg} / \mathrm{L}$ MWCNT and solvent control. (b) Gene expression pattern of female O. latipes exposed to $100 \mathrm{mg} / \mathrm{L}$ MWCNT and solvent control. The initials S and T followed by gene name reveal the solvent control group and MWCNT treated group, respectively. For example, Cas3t is the Cas3 expression pattern of MWCNT treated group and Cas3s is the pattern of solvent control group. Columns and error bars represent the mean \pm SD. Asterisk indicates values that are significantly higher than control values $\left({ }^{*} P<0.05\right.$; $t$-test, $\left.n=7\right)$.

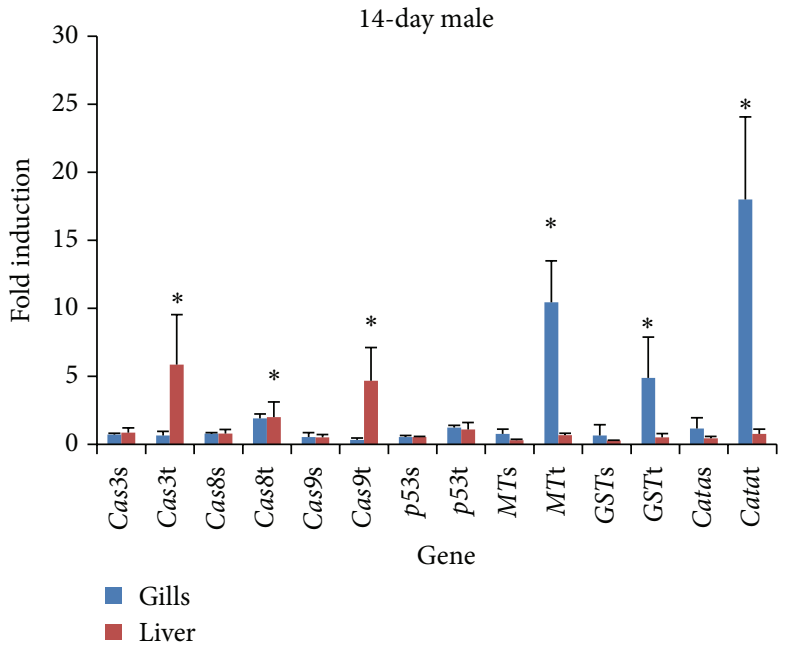

(a)

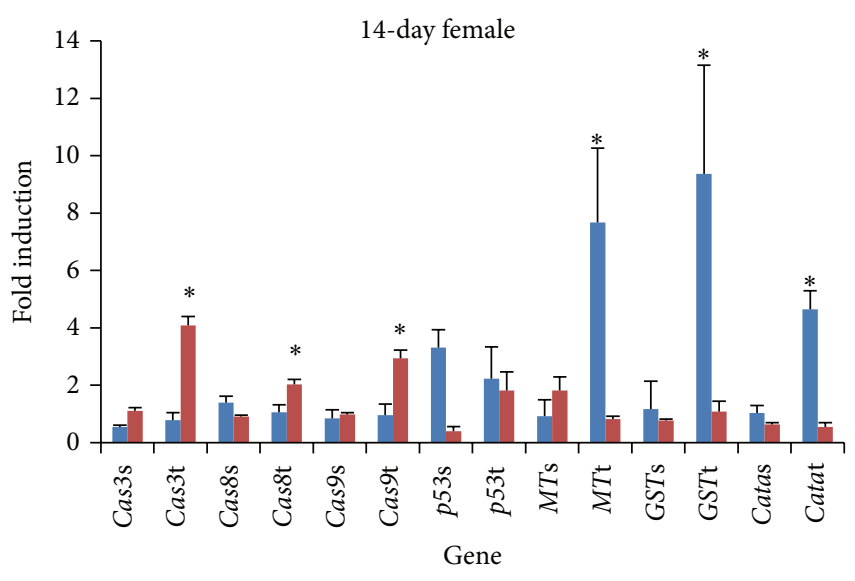

Gills

- Liver

(b)

Figure 5: mRNA induction at 14 days. (a) Gene expression pattern of male O. latipes exposed to $100 \mathrm{mg} / \mathrm{L}$ MWCNT and solvent control. (b) Gene expression pattern of female O. latipes exposed to $100 \mathrm{mg} / \mathrm{L}$ MWCNT and solvent control. The initials $\mathrm{S}$ and T followed by gene name reveal the solvent control group and MWCNT treated group, respectively. For example, Cas3t is the Cas3 expression pattern of MWCNT treated group and Cas3s is the pattern of solvent control group. Columns and error bars represent the mean \pm SD. Asterisk indicates values that are significantly higher than control values $\left({ }^{*} P<0.05 ;\right.$-test, $\left.n=7\right)$.

controls in the liver was higher in males than females, but the difference between males and females was significant only for Cas9.

Differences in the induction of apoptosis gene were found among the gills, liver, and intestine. At 4 days, significant induction of expression relative to the controls was found only in the gills, thus not the liver, while at 14 days significant induction of expression was found only in the liver, not the gills. Cas 8 and Cas 9 expression was induced to a significantly greater degree in the gills than the liver.

\section{Discussions}

Scanning and transmission electron microscopy showed MWCNTs, and not some other form of carbon nanoparticle 
or amorphous carbon (Figure 1). There was no significant alteration of hydrodynamic size, Zeta-potential, and stability index during MWCNT exposure. Therefore, any toxicological outcomes identified in this study are attributable to MWCNT exposure.

Intracellular ROS generation was measured using a dichlorofluorescein-diacetate method. No significant ROS induction relative to the controls was observed in any tissue at 4 days in which a decrease in antioxidant gene expression was found. These results are contradictory. Some studies revealed ROS induction caused by carbon nanotubes $[8,9,14,16,44-$ 46], while others failed to detect ROS in vitro or in vivo [39, 47-50]. Daphnia magna exposed to MWCNT did not cause ROS induction [39]. Kagan et al. [51] demonstrated that neither purified $(0.23 \mathrm{wt}$. \% of iron) nor nonpurified CNTs (26 wt. \% of iron) led to intracellular production of superoxide radicals in RAW 264.7 macrophages, while CNTs generated hydroxyl radicals in zymosan-stimulated RAW 264.7 macrophages. Any metal impurities from MWCNT can also induce ROS [29]. Nevertheless, at 4 days, no such ROS induction was observed. Fenoglio et al. [52] stated that CNTs could scavenge hydroxyl radicals produced by the Fenton reaction. Furthermore, after 4 days of MWCNT exposure, no induction of MT expression was evident. Together, these results suggest that metal impurities did not participate in ROS production.

At 14 days, ROS induction was observed with simultaneous significant induction of antioxidant and $M T$ gene expression in the gills. Previous studies showed the ROS can be induced by metal impurities from carbon nanotubes. Ultrasonication used in many studies including this work to disperse carbon nanotube in water increased bioavailability of metal impurities [53]. The ROS production induced by the metal impurities (especially iron) from carbon nanotube was observed [29, 37, 51]. The bioaccumulation of metals, such as iron in fish liver and gills, has been reported $[1,54]$. So, we postulate that after 4 days of MWCNT exposure, insufficient metal impurities have not been accumulated to the necessary threshold level and MWCNTs scavenge any hydroxyl radicals produced by the metal impurities, likely repressing antioxidant gene expression and ROS increase. By 14 days, however, sufficient metal impurities might be accumulated to overcome the antioxidant depletion and MWCNT scavenging activity, leading to significantly increased $M T$ and antioxidant gene expression. Together, these results suggest that the significant increase in antioxidant and $M T$ gene expression at 14 days may be due to the effects of metal impurities as well as MWCNTs.

The expression levels of antioxidant genes were reduced significantly relative to the controls at 4 days. This result was observed in other studies in which rodents or cells were exposed to MWCNTs $[9,11,14,30,46,55,56]$. Those studies mentioned that the prooxidant effects of engineered nanomaterials were mediated by depletion of antioxidants. Such perturbations of the normal redox state contribute to peroxide and free radical production, which has adverse effects on proteins, lipids, and DNA [30]. Reduced GST, $C A T$, and $S O D$ gene expression and decreased protein activity were also found in studies in which fish were exposed to $\mathrm{Ag}$ and $\mathrm{ZnO}$ nanoparticles [57-59]. Thus, it is postulated that antioxidant depletion observed in this work might be caused specifically by nanosize particles irrespective of the type of nanomaterial as well as the CNT capacity which scavenge ROS.

At 4 days, significant induction of apoptosis gene ( $p 53$, Cas3, Cas8, and Cas9) expression in the gills was observed relative to the controls on exposure to $100 \mathrm{mg} / \mathrm{L}$ MWCNTs, while there was no significant induction of expression in the liver or intestine. The proteases encoded by Cas3, Cas 8 , and Cas 9 play pivotal roles in the apoptosis pathway. In addition, p53 plays an important role in cell cycle control and apoptosis by activating various proapoptotic genes, such as $B a x$ [60]. In previous studies, Cas3, Cas 8 , and Cas 9 expression was found to be an indicator of MWCNT-induced apoptosis $[9,13,15]$. Previous studies also demonstrated that MWCNT induced p53-dependent apoptosis [9, 61]. At 14 days, no significant induction of apoptosis gene expression was found in the gills. However, Cas3, Cas 8 , and Cas9 expression increased significantly in liver. The fold induction was lower than that in the gills at 4 days. Therefore, ca. 14 days are needed for MWCNT-induced apoptosis to affect the liver. Several studies showed that MWCNT could translocate to other organs of the body through barrier organ such as lung, causing systemic side effects $[62,63]$. Thus, it is likely that translocation of MWCNT can be the reason of apoptosis occurrence in liver. In addition, metal impurities can also cause ROSdependent apoptosis. However, since there was no significant induction of the expression of $M T$ or antioxidant genes in the liver, whether metal impurities caused the apoptosis gene induction in the liver at 14 days is unclear. Overall, these results suggest that MWCNT dispersed in water can cause apoptosis occurrence in gill and liver of fish at different exposure period.

In this work, significant gender differences were found. Previous studies demonstrated that estradiol or endocrinedisruptor chemicals could induce the expression of antioxidant genes, such as GST, but reduce CAT and MT expression $[24,28,64]$. At 14 days, the GST induction relative to the controls was higher in females than males, albeit not significantly so, while the induction of $M T$ and $C A T$ expression was significantly higher in males. At 4 days, antioxidant gene expression was reduced relative to the controls. In males, $C A T$ expression was reduced to a significantly extent than in females. This result differs from previous reports. The MWCNT-induced expression of apoptosis gene differed according to gender. The fold induction of Cas3, Cas8, Cas9, and $p 53$ expression relative to the controls was significantly higher in male than female fish at 4 days after exposure to $100 \mathrm{mg} / \mathrm{L}$ MWCNT. Previous studies demonstrated that estrogen repressed p53-dependent apoptosis [23, 27]. Bailey et al. [27] reported that a small set of proapoptotic $p 53$ target genes is also targeted by the estrogen receptor (ER).

The differences in apoptosis and antioxidant gene expression among tissues were analyzed. Only gills showed significantly increased gene expression at 4 days. As mentioned above, the mechanisms of MWCNT-induced apoptosis and antioxidant depletion are unclear. MWCNTs can lead to frustrated phagocytosis, which would results in release of 
superoxide produced in macrophage phagosomes into intraand extracellular space $[31,32,65,66]$. Previously, several studies showed that superoxide fluxes can cross the endothelial cell plasma membrane via the chloride channel (CLC-3), causing intracellular ROS stress and apoptosis [13, 33, 34]. CLC-3 can be induced by specific environmental stresses, such as anion alteration, at higher levels in gills than in the liver or intestine $[67,68]$. Therefore, the influence caused by MWCNT exposure could lead to the expression of CLC-3 channels through which superoxide translocates, to a greater extent in the gills than in the liver or intestine. Further investigation of tissue differences in MWCNT-induced ROS and apoptosis production is needed.

In the histological study, no apoptosis or inflammation was found after MWCNT exposure for 21 days (Suppl. Figure 1) (see Supplementary Material available online at http://dx.doi.org/10.1155/2014/485343). van der Oost et al. [1] reported that a molecular-level response to chemicals occurs before tissue-level effects are evident. Therefore, it is necessary to assess the correlation between the biological responses to MWCNTs at the molecular and tissue levels by means of tests involving prolonged MWCNT exposure.

In summary, this study showed that MWCNT exposure could cause antioxidant depletion and p53-dependent apoptosis. The expression of relevant genes was influenced by exposure duration and differed according to gender and tissue type.

\section{Conflict of Interests}

The authors declare that there is no conflict of interests regarding the publication of this paper

\section{Acknowledgment}

This study was supported by the research project for Environmental Risk Assessment of Manufactured Nanomaterials (KK-1303-03) funded by the Korea Institute of Toxicology (KIT, Korea).

\section{References}

[1] R. van der Oost, J. Beyer, and N. P. E. Vermeulen, "Fish bioaccumulation and biomarkers in environmental risk assessment: a review," Environmental Toxicology and Pharmacology, vol. 13, no. 2, pp. 57-149, 2003.

[2] L. R. Parenti, "A phylogenetic analysis and taxonomic revision of ricefishes, Oryzias and relatives (Beloniformes, Adrianichthyidae)," Zoological Journal of the Linnean Society, vol. 154, no. 3 , pp. 494-610, 2008.

[3] Y. Chen, S. F. Zeng, and Y. F. Cao, "Environmental assess, oxidative stress response in zebra fish gill experimentally exposed to subchronic microcystin-LR," Environmental Monitoring and Assessment, vol. 184, no. 11, pp. 6775-6787, 2012.

[4] J. Costa, M. Ferreira, L. Rey-Salgueiro, and M. A. ReisHenriques, "Comparision of the waterborne and dietary routes of exposure on the effects of Benzo(a)pyrene on biotransformation pathways in Nile tilapia (Oreochromis niloticus)," Chemosphere, vol. 84, no. 10, pp. 1452-1460, 2011.
[5] J. W. Lee, Y. H. Kim, S. Yoon, and S. K. Lee, "Cytochrome P450 system expression and DNA adduct formation in the liver of Zacco platypus following waterborne $\operatorname{Benzo}(a)$ pyrene exposure: implications for biomarker determination," Environmental Toxicology, vol. 13, no. 4, pp. 1032-1042, 2012.

[6] L. Vaisman, H. D. Wagner, and G. Marom, "The role of surfactants in dispersion of carbon nanotubes," Advances in Colloid and Interface Science, vol. 128-130, pp. 37-46, 2006.

[7] P. J. F. Harris, Carbon Nanotube Science, Cambridge University Press, Cambridge, UK, 2009.

[8] X. He, S.-H. Young, D. Schwegler-Berry, W. P. Chisholm, J. E. Fernback, and Q. Ma, "Multiwalled carbon nanotubes induce a fibrogenic response by stimulating reactive oxygen species production, activating NF- $\kappa \mathrm{B}$ signaling, and promoting fibroblastto-myofibroblast transformation," Chemical Research in Toxicology, vol. 24, no. 12, pp. 2237-2248, 2011.

[9] P. Ravichandran, S. Baluchamy, R. Gopikrishnan et al., "Pulmonary biocompatibility assessment of inhaled single-wall and multiwall carbon nanotubes in BALB/c mice," The Journal of Biological Chemistry, vol. 286, no. 34, pp. 29725-29733, 2011.

[10] X. Cheng, J. Zhong, J. Meng et al., "Characterization of multiwalled carbon nanotubes dispersing in water and association with biological effects," Journal of Nanomaterials, vol. 2011, Article ID 938491, 12 pages, 2011.

[11] T. W. K. Fraser, H. C. Reinardy, B. J. Shaw, T. B. Henry, and R. D. Handy, "Dietary toxicity of single-walled carbon nanotubes and fullerenes $\left(\mathrm{C}_{60}\right)$ in rainbow trout (Oncorhynchus mykiss)," Nanotoxicology, vol. 5, no. 1, pp. 98-108, 2011.

[12] M. M. Pereira, L. Mouton, C. Yéprémian et al., "Ecotoxicological effects of carbon nanotubes and cellulose nanofibers in Chlorella vulgaris," Journal of Nanobiotechnology, vol. 12, no. 1, article 15, 2014.

[13] X. Wang, J. Guo, T. Chen et al., "Multi-walled carbon nanotubes induce apoptosis via mitochondrial pathway and scavenger receptor," Toxicology in Vitro, vol. 26, no. 6, pp. 799-806, 2012.

[14] B. Chen, Y. Liu, W. M. Song, Y. Hayashi, X. C. Ding, and W. $\mathrm{H}$. Li, "In vitro evaluation of cytotoxicity and oxidative stress induced by multiwalled carbon nanotubes in murine RAW 264.7 macrophages and human A549 Lung cells," Biomedical and Environmental Sciences, vol. 24, no. 6, pp. 593-601, 2011.

[15] S. K. Sohaebuddin, P. T. Thevenot, D. Baker, J. W. Eaton, and L. Tang, "Nanomaterial cytotoxicity is composition, size, and cell type dependent," Particle and Fibre Toxicology, vol. 7, article 22, 2010.

[16] P. Ravichandran, S. Baluchamy, B. Sadanandan et al., "Multiwalled carbon nanotubes activate NF- $\kappa$ B and AP-1 signaling pathways to induce apoptosis in rat lung epithelial cells," Apoptosis, vol. 15, no. 12, pp. 1507-1516, 2010.

[17] J. E. Choi, S. Kim, J. H. Ahn et al., "Induction of oxidative stress and apoptosis by silver nanoparticles in the liver of adult zebrafish," Aquatic Toxicology, vol. 100, no. 2, pp. 151-159, 2010.

[18] L. HAO, Z. WANG, and B. XING, "Effect of sub-acute exposure to $\mathrm{TiO}_{2}$ nanoparticles on oxidative stress and histopathological changes in Juvenile Carp (Cyprinus carpio)," Journal of Environmental Sciences, vol. 21, no. 10, pp. 1459-1466, 2009.

[19] T. Wang, X. Long, Y. Cheng, Z. Liu, and S. Yan, “The potential toxicity of copper nanoparticles and copper sulphate on juvenile Epinephelus coioides," Aquatic Toxicology, vol. 152, pp. 96-104, 2014.

[20] S. Neeta, "Apoptosis in health and disease and modulation of apoptosis for therapy: an overview," Indian Journal of Clinical Biochemistry, vol. 22, no. 2, pp. 6-16, 2007. 
[21] T. J. Van Ham, J. Mapes, D. Kokel, and R. T. Peterson, "Live imaging of apoptotic cells in zebrafish," The FASEB Journal, vol. 24, no. 11, pp. 4336-4342, 2010.

[22] M. J. Evans, S. MacLaughlin, R. D. Marvin, and N. I. Abdou, "Estrogen decreases in vitro apoptosis of peripheral blood mononuclear cells from women with normal menstrual cycles and decreases TNF- $\alpha$ production in SLE but not in normal cultures," Clinical Immunology and Immunopathology, vol. 82, no. 3, pp. 258-262, 1997.

[23] B. Perillo, A. Sasso, C. Abbondanza, and G. Palumbo, "17 $\beta$ estradiol inhibits apoptosis in MCF-7 cells, inducing bcl-2 expression via two estrogen-responsive elements present in the coding sequence," Molecular \& Cellular Biology, vol. 20, no. 8, pp. 2890-2901, 2000.

[24] E. A. Stokes, W. Lonergan, L. P. Weber et al., "Decreased apoptosis in the forebrain of adult male medaka (Oryzias latipes) after aqueous exposure to ethinylestradiol," Comparative Biochemistry and Physiology C: Toxicology and Pharmacology, vol. 138, no. 2, pp. 163-167, 2004.

[25] M. Cutolo, S. Capellino, P. Montagna, P. Ghiorzo, A. Sulli, and B. Villaggio, "Sex hormone modulation of cell growth and apoptosis of the human monocytic/macrophage cell line," Arthritis Research \& Therapy, vol. 7, no. 5, pp. R1124-R1132, 2005.

[26] H. Thilagam, S. Gopalakrishnan, H.-D. Qu, J. Bo, and K.-J. Wang, " $17 \beta$ estradiol induced ROS generation, DNA damage and enzymatic responses in the hepatic tissue of Japanese sea bass," Ecotoxicology, vol. 19, no. 7, pp. 1258-1267, 2010.

[27] S. T. Bailey, H. Shin, T. Westerling, X. S. Liu, and M. Brown, "Estrogen receptor prevents p53-dependent apoptosis in breast cancer," Proceedings of the National Academy of Sciences of the United States of America, vol. 109, no. 44, pp. 18060-18065, 2012.

[28] S. Woo, H. Won, A. Lee, and S. Yum, "Oxidative stress and gene expression in diverse tissues of Oryzias javanicus exposed to $17 \beta$-estradiol," Molecular and Cellular Toxicology, vol. 8, no. 3, pp. 263-269, 2012.

[29] A. A. Shvedova, A. Pietroiusti, B. Fadeel, and V. E. Kagan, "Mechanisms of carbon nanotube-induced toxicity: focus on oxidative stress," Toxicology and Applied Pharmacology, vol. 261, no. 2, pp. 121-133, 2012.

[30] A. Manke, L. Wang, and Y. Rojanasakul, "Mechanisms of nanoparticle-induced oxidative stress and toxicity," BioMed Research International, vol. 2013, Article ID 942916, 15 pages, 2013.

[31] D. M. Brown, I. A. Kinloch, U. Bangert et al., "An in vitro study of the potential of carbon nanotubes and nanofibres to induce inflammatory mediators and frustrated phagocytosis," Carbon, vol. 45, no. 9, pp. 1743-1756, 2007.

[32] K. Donaldson, F. A. Murphy, R. Duffin, and C. A. Poland, "Asbestos, carbon nanotubes and the pleural mesothelium: a review of the hypothesis regarding the role of long fibre retention in the parietal pleura, inflammation and mesothelioma," Particle and Fibre Toxicology, vol. 7, article 5, 2010.

[33] M. Madesh, B. J. Hawkins, T. Milovanova et al., "Selective role for superoxide in InsP3 receptor-mediated mitochondrial dysfunction and endothelial apoptosis," The Journal of Cell Biology, vol. 170, no. 7, pp. 1079-1090, 2005.

[34] B. J. Hawkins, M. Madesh, C. J. Kirkpatrick, and A. B. Fisher, "Superoxide flux in endothelial cells via the chloride channel-3 mediates intracellular signaling," Molecular Biology of the Cell, vol. 18, no. 6, pp. 2002-2012, 2007.
[35] M. Valko, C. J. Rhodes, J. Moncol, M. Izakovic, and M. Mazur, "Free radicals, metals and antioxidants in oxidative stressinduced cancer," Chemico-Biological Interactions, vol. 160, no. 1, pp. 1-40, 2006.

[36] S. Bates and K. H. Vousden, "Mechanisms of p53-mediated apoptosis," Cellular and Molecular Life Sciences, vol. 55, no. 1, pp. 28-37, 1999.

[37] C. Ge, Y. Li, J. J. Yin et al., "The contributions of metal impurities and tube structure to the toxicity of carbon nanotube materials," NPG Asia Materials, vol. 4, no. 12, article e32, 2012.

[38] C. J. Smith, B. J. Shaw, and R. D. Handy, "Toxicity of single walled carbon nanotubes to rainbow trout, (Oncorhynchus mykiss): respiratory toxicity, organ pathologies, and other physiological effects," Aquatic Toxicology, vol. 82, no. 2, pp. 94-109, 2007.

[39] K.-T. Kim, A. J. Edgington, S. J. Klaine, J.-W. Cho, and S. D. Kim, "Influence of multiwalled carbon nanotubes dispersed in natural organic matter on speciation and bioavailability of copper," Environmental Science and Technology, vol. 43, no. 23, pp. 8979-8984, 2009.

[40] X. Zhu, L. Zhu, Y. Chen, and S. Tian, "Acute toxicities of six manufactured nanomaterial suspensions to Daphnia magna," Journal of Nanoparticle Research, vol. 11, no. 1, pp. 67-75, 2009.

[41] E. J. Petersen, J. Akkanen, J. V. K. Kukkonen, and W. J. Weber Jr., "Biological uptake and depuration of carbon nanotubes by Daphnia magna," Environmental Science and Technology, vol. 43, no. 8, pp. 2969-2975, 2009.

[42] J. Cheng and S. H. Cheng, "Influence of carbon nanotube length on toxicity to zebrafish embryos," International Journal of Nanomedicine, vol. 7, pp. 3731-3739, 2012.

[43] K. J. Livak and T. D. Schmittgen, "Analysis of relative gene expression data using real-time quantitative PCR and the $2^{-\triangle \triangle C T}$ method," Methods, vol. 25, no. 4, pp. 402-408, 2001.

[44] C. S. Sharma, S. Sarkar, A. Periyakaruppan et al., "Single-walled carbon nanotubes induces oxidative stress in rat lung epithelial cells," Journal of Nanoscience and Nanotechnology, vol. 7, no. 7, pp. 2466-2472, 2007.

[45] T. Thurnherr, C. Brandenberger, K. Fischer et al., "A comparison of acute and long-term effects of industrial multiwalled carbon nanotubes on human lung and immune cells in vitro," Toxicology Letters, vol. 200, no. 3, pp. 176-186, 2011.

[46] Y. Y. Guo, J. Zhang, Y. F. Zheng, J. Yang, and X. Q. Zhu, "Cytotoxic and genotoxic effects of multi-wall carbon nanotubes on human umbilical vein endothelial cells in vitro," Mutation Research - Genetic Toxicology and Environmental Mutagenesis, vol. 721, no. 2, pp. 184-191, 2011.

[47] H. L. Karlsson, P. Cronholm, J. Gustafsson, and L. Möller, "Copper oxide nanoparticles are highly toxic: a comparison between metal oxide nanoparticles and carbon nanotubes," Chemical Research in Toxicology, vol. 21, no. 9, pp. 1726-1732, 2008.

[48] I. Fenoglio, G. Greco, M. Tomatis et al., "Structural defects play a major role in the acute lung toxicity of multiwall carbon nanotubes: physicochemical aspects," Chemical Research in Toxicology, vol. 21, no. 9, pp. 1690-1697, 2008.

[49] H. Xu, J. Bai, J. Meng, W. Hao, H. Xu, and J.-M. Cao, "Multiwalled carbon nanotubes suppress potassium channel activities in PC12 cells," Nanotechnology, vol. 20, no. 28, Article ID 285102, 2009.

[50] O. Vittorio, V. Raffa, and A. Cuschieri, "Influence of purity and surface oxidation on cytotoxicity of multiwalled carbon 
nanotubes with human neuroblastoma cells," Nanomedicine: Nanotechnology, Biology, and Medicine, vol. 5, no. 4, pp. 424431, 2009.

[51] V. E. Kagan, Y. Y. Tyurina, V. A. Tyurin et al., "Direct and indirect effects of single walled carbon nanotubes on RAW 264.7 macrophages: role of iron," Toxicology Letters, vol. 165, no. 1, pp. 88-100, 2006.

[52] I. Fenoglio, M. Tomatis, D. Lison et al., "Reactivity of carbon nanotubes: free radical generation or scavenging activity?" Free Radical Biology and Medicine, vol. 40, no. 7, pp. 1227-1233, 2006.

[53] R. J. Toh, A. Ambrosi, and M. Pumera, "Bioavailability of metallic impurities in carbon nanotubes is greatly enhanced by ultrasonication," Chemistry, vol. 18, no. 37, pp. 11593-11596, 2012.

[54] G. R. Phillips and R. C. Russo, "Metal bioaccumulation in fishes and aquatic invertebrates: a literature review," EPA 600/3-78103, US EPA, 1978.

[55] H. Yang, C. Liu, D. Yang, H. Zhang, and Z. Xi, "Comparative study of cytotoxicity, oxidative stress and genotoxicity induced by four typical nanomaterials: the role of particle size, shape and composition," Journal of Applied Toxicology, vol. 29, no. 1, pp. 69-78, 2009.

[56] A. R. N. Reddy, M. V. Rao, D. R. Krishna, V. Himabindu, and Y. N. Reddy, "Evaluation of oxidative stress and anti-oxidant status in rat serum following exposure of carbon nanotubes," Regulatory Toxicology and Pharmacology, vol. 59, no. 2, pp. 251257, 2011.

[57] Y. J. Chae, C. H. Pham, J. Lee, E. Bae, J. Yi, and M. B. Gu, "Evaluation of the toxic impact of silver nanoparticles on Japanese medaka (Oryzias latipes)," Aquatic Toxicology, vol. 94, no. 4, pp. 320-327, 2009.

[58] B. Lee, C. N. Duong, J. Cho et al., “Toxicity of citrate-capped silver nanoparticles in common carp (Cyprinus carpio)," Journal of Biomedicine and Biotechnology, vol. 2012, Article ID 262670, 14 pages, 2012.

[59] L. Hao and L. Chen, "Oxidative stress responses in different organs of carp (Cyprinus carpio) with exposure to $\mathrm{ZnO}$ nanoparticles," Ecotoxicology and Environmental Safety, vol. 80, pp. 103-110, 2012.

[60] K. H. Vousden, “p53: death star," Cell, vol. 103, no. 5, pp. 691-694, 2000.

[61] P. Ravichandran, A. Periyakaruppan, B. Sadanandan et al., "Induction of apoptosis in rat lung epithelial cells by multiwalled carbon nanotubes," Journal of Biochemical and Molecular Toxicology, vol. 23, no. 5, pp. 333-344, 2009.

[62] B. Czarny, D. Georgin, B. Fannely et al., "Carbon nanotube translocation to distant organs after pulmonary exposure: insights from in Situ 14C-Radiolabeling and tissue radioimaging," ACS Nano, vol. 8, no. 6, pp. 5715-5724, 2014.

[63] A. A. Shvedova and V. E. Kagan, "The role of nanotoxicology in realizing the "helping without harm" paradigm of nanomedicine: lessons from studies of pulmonary effects of single-walled carbon nanotubes," Journal of Internal Medicine, vol. 267, no. 1, pp. 106-118, 2010.

[64] M. Gerpe, P. Kling, A. H. Berg, and P.-E. Olsson, "Arctic char (Salvelinus alpinus) metallothionein: cDNA sequence, expression, and tissue-specific inhibition of cadmium-mediated metallothionein induction by $17 \beta$-estradiol, $4-\mathrm{OH}-\mathrm{PCB} 30$, and PCB 104," Environmental Toxicology and Chemistry, vol. 19, no. 3, pp. 638-645, 2000.

[65] I. M. Hill, P. H. Beswick, and K. Donaldson, "Differential release of superoxide anions by macrophages treated with long and short fibre amosite asbestos is a consequence of differential affinity for opsonin," Occupational and Environmental Medicine, vol. 52, no. 2, pp. 92-96, 1995.

[66] L. A. Goodglick and A. B. Kane, "Role of reactive oxygen metabolites in crocidolite asbestos toxicity to mouse macrophages," Cancer Research, vol. 46, no. 11, pp. 5558-5566, 1986.

[67] C.-H. Tang, L.-Y. Hwang, and T.-H. Lee, "Chloride channel CLC-3 in gills of the euryhaline teleost, Tetraodon nigroviridis: expression, localization and the possible role of chloride absorption," The Journal of Experimental Biology, vol. 213, no. 5, pp. 683-693, 2010.

[68] C.-H. Tang and T.-H. Lee, "Ion-deficient environment induces the expression of basolateral chloride channel, ClC-3-like protein, in gill mitochondrion-rich cells for chloride uptake of the tilapia Oreochromis mossambicus," Physiological and Biochemical Zoology, vol. 84, no. 1, pp. 54-67, 2011. 

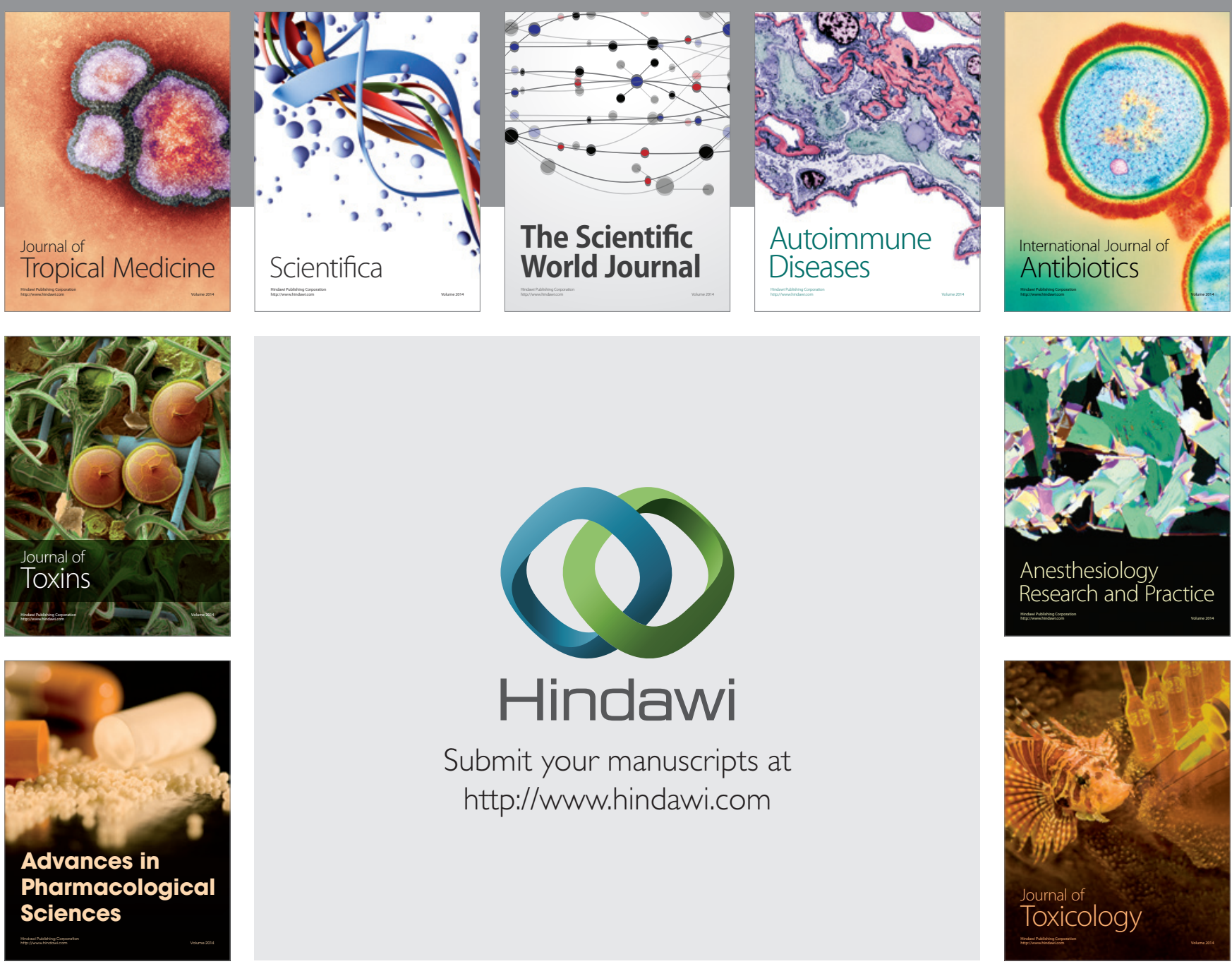

\section{Hindawi}

Submit your manuscripts at

http://www.hindawi.com
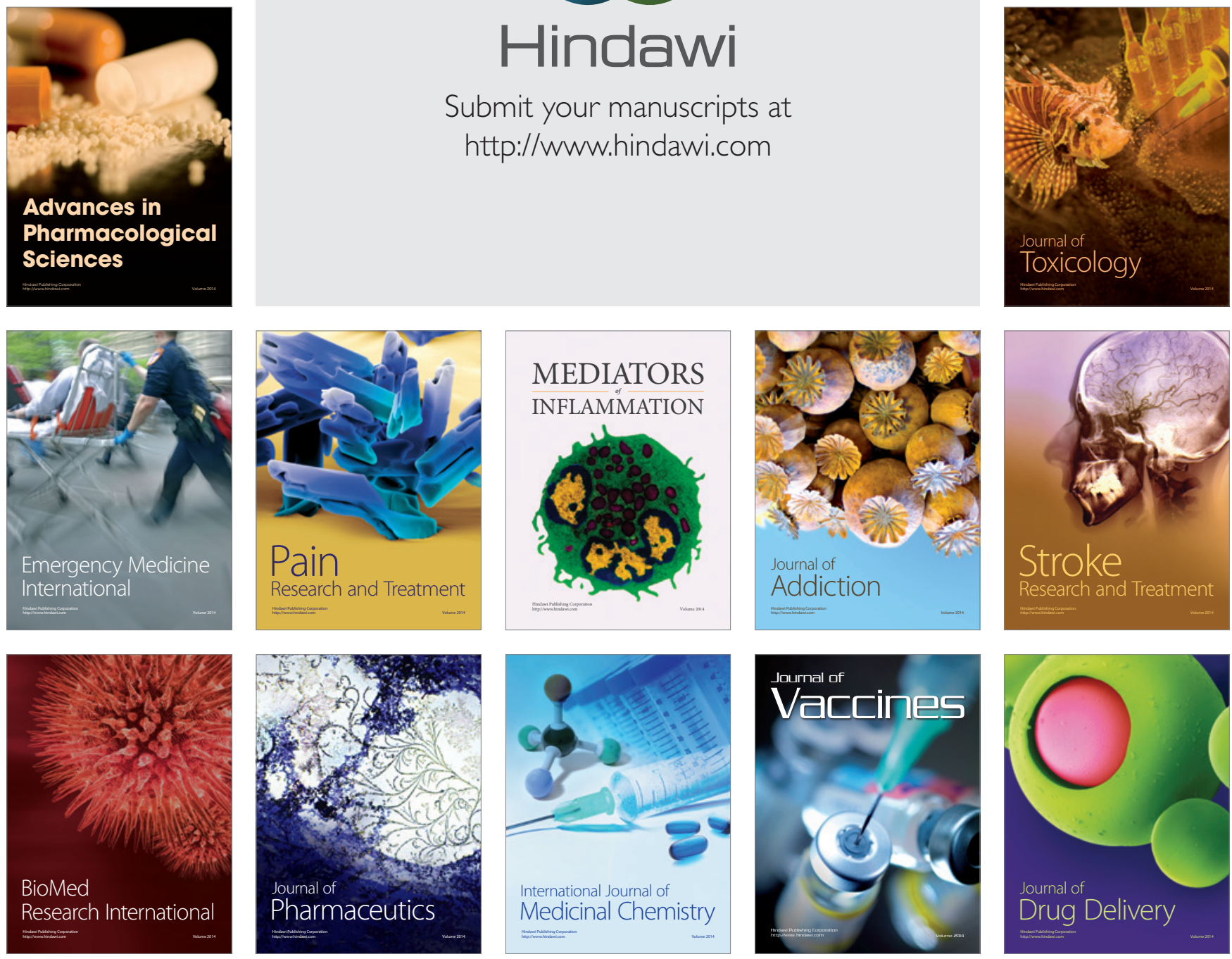